\title{
Effect of machining conditions on MRR and surface roughness during CNC Turning of different Materials Using TiN Coated Cutting Tools - A Taguchi approach
}

\author{
H. K. Dave ${ }^{\mathrm{a}^{*}}$, L. S. Patel ${ }^{\mathrm{b}}$ and H. K. Raval ${ }^{\mathrm{a}}$
}

${ }^{a}$ Department of Mechanical Engineering, S. V. National Institute of Technology, Surat-395007, India

${ }^{b}$ Department of Mechanical Engineering, STBS College of Diploma Engg., Surat -395006, India

\begin{tabular}{|c|c|}
\hline A R T I C L E I N F O & ABSTRACT \\
\hline $\begin{array}{l}\text { Article history: } \\
\text { Received 5 January } 2012 \\
\text { Accepted April } 202012 \\
\text { Available online } \\
\text { 25 April } 2012 \\
\text { Keywords: } \\
\text { Dry turning } \\
\text { Surface roughness } \\
\text { Material removal rate } \\
\text { Taguchi method } \\
\text { ANOVA } \\
\text { Tin Coated cutting tools }\end{array}$ & $\begin{array}{l}\text { This paper presents on experimental investigation of the machining characteristics of different } \\
\text { grades of EN materials in CNC turning process using TiN coated cutting tools. In machining } \\
\text { operation, the quality of surface finish is an important requirement for many turned work pieces. } \\
\text { Thus, the choice of optimized cutting parameters is very important for controlling the required } \\
\text { surface quality. The purpose of this research paper is focused on the analysis of optimum cutting } \\
\text { conditions to get the lowest surface roughness and maximum material removal rate in CNC } \\
\text { turning of different grades of EN materials by Taguchi method. Optimal cutting parameters for } \\
\text { each performance measure were obtained employing Taguchi techniques. The orthogonal array, } \\
\text { signal to noise ratio and analysis of variance were employed to study the performance } \\
\text { characteristics in dry turning operation. ANOVA has shown that the depth of cut has significant } \\
\text { role to play in producing higher MRR and insert has significant role to play for producing lower } \\
\text { surface roughness. Thus, it is possible to increase machine utilization and decrease production } \\
\text { cost in an automated manufacturing environment. }\end{array}$ \\
\hline
\end{tabular}

\section{Introduction}

In today's competitive and dynamic market environment, large or small manufacturing industries, have mostly assigned a high priority to economic machining due to sensitiveness of machining conditions to production optimization. Increasing the productivity and the quality of the machined parts are the main challenges of metal-based industry; there has been increased interest in monitoring all aspects of the machining process. Turning is the most widely used among all the cutting processes. The increasing importance of turning operations is gaining new dimensions in the present industrial age, in which the growing competition calls for all the efforts to be directed towards the economical manufacture of machined parts and surface finish is one of the most critical quality measures in mechanical products. As the competition grows closer, customer now have increasingly high demands on quality, making surface roughness one of the most competitive parameters in today's manufacturing industry. In a machining operation, selection of cutting parameters is the most critical job (Jayant \& Kumar, 2008).

* Corresponding author.

E-mail: harshitkumar@yahoo.com (H. K. Dave)

(C) 2012 Growing Science Ltd. All rights reserved. doi: $10.5267 /$ j.ijiec.2012.04.005 
Hence, there is a need for a systematic methodological approach by using experimental methods and statistical/mathematical models. The design of experiments (DOE) is an efficient procedure for the purpose of planning experiments. Furthermore, the data can be analyzed to obtain valid and objective conclusions (Kaladhar et al., 2010). The Taguchi method is statistical tool, adopted experimentally to investigate influence of surface roughness by cutting parameters such as cutting speed, feed and depth of cut (Thamizhmanii, 2007). The Taguchi process helps select or determine the optimum cutting conditions for turning process. Many researchers developed many mathematical models to optimize the cutting parameters to get the lowest surface roughness and maximum material removal rate by turning process. The variation in the material hardness, alloying elements present in the work piece material and other factors affecting surface finish and material removal rate.

\section{Experimental procedure}

Turning is a popularly used machining process. The CNC machines play a major role in modern machining industry to enhance product quality as well as productivity. Batliboi make CNC turning centre is used to carry out the experimentation. The machine has capability to adjust 8 different parameters out of which 5 are used in current study. The CNC machine used in experiments as shown in Fig. 1.

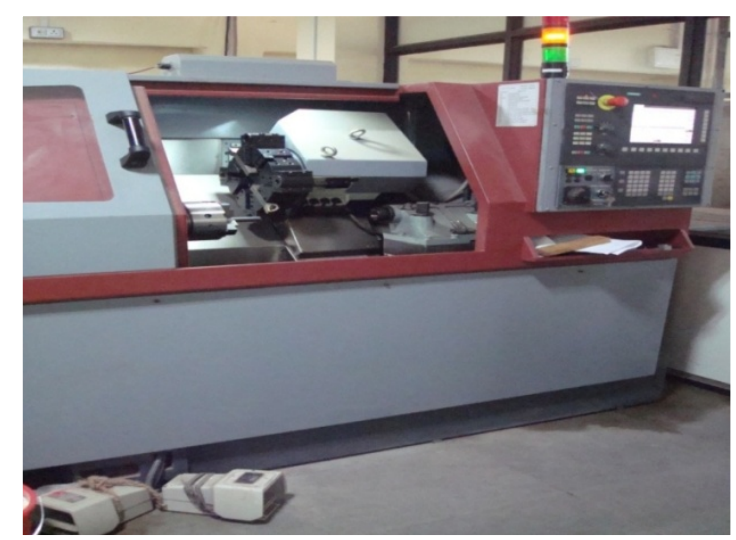

\subsection{Selection of work piece Material}

Fig. 1. Experimental Set Up

In the present study, different materials like EN-8 and EN-31 are used as work piece. EN8 is an unalloyed medium carbon steel with good tensile strength. It is normally supplied in cold drawn or as rolled. Tensile properties can vary but are usually between $500-800 \mathrm{~N} / \mathrm{mm}^{2}$. EN8 is available from stock in bar and can be cut to our requirements. Chemical compositions of EN 8 and EN31 are as given below in table 1 and 2 respectively (Arora, 2010).

Table 1

Chemical Composition Of EN8

\begin{tabular}{ccccc}
\hline $\mathrm{C}$ & $\mathrm{Si}$ & $\mathrm{Mn}$ & $\mathrm{S}$ & $\mathrm{P}$ \\
\hline $0.40 \%$ & $0.25 \%$ & $0.80 \%$ & $0.02 \%$ & $0.02 \%$ \\
\hline
\end{tabular}

EN31 is an unalloyed carbon with better tensile strength and its composition is slightly different from EN 8 in terms of percentage except, which has a very little or no phosphorus.

Table 2

Chemical Composition Of EN31

\begin{tabular}{cccc}
\hline $\mathrm{C}$ & $\mathrm{Si}$ & $\mathrm{Mn}$ & $\mathrm{Cr}$ \\
\hline $1.00 \%$ & $0.20 \%$ & $0.50 \%$ & $1.40 \%$ \\
\hline
\end{tabular}


Each work piece is cut in size of $20 \mathrm{~mm}$ diameter $\times 100 \mathrm{~mm}$ length and, after turning $(50 \mathrm{~mm}$ length and different depth of cut), is performed on $\mathrm{CNC}$ turning centre. Turning program is prepared and feed in the CNC machine.

\subsection{Selection of Cutting Tools and tool holders}

The cutting tool selected for present work is coated (TiN) carbides (Tungsten) inserts and Taegutec catalog is used for selection of cutting tool for machining different grades of EN materials.

Based on the catalog, following two different types of inserts (ISO coding) are used in present work.

1. CNMG 120408 MT TT 1500 (CVD Coated)

2. CCMT 09T304 FG TT 8020 (PVD Coated)

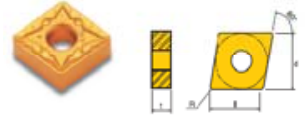

CNMG 120408 MT TT 1500

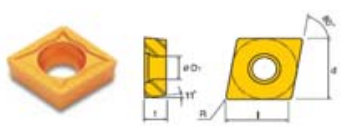

CCMT 09T304 FG TT 8020

Fig. 2. Cutting inserts

The tool geometry of the inserts are as follows.

Insert CNMG (CVD coated) - Rhombic $80^{\circ}$,insert clearance angle $0^{\circ}$ (Negative),cutting edge length$12 \mathrm{~mm}$,insert thickness- $5 \mathrm{~mm}$,nose radius $-0.8 \mathrm{~mm}$.

Insert CCMT (PVD Coated) - Rhombic $80^{\circ}$, insert clearance angle $11^{\circ}$ (positive),cutting edge length$9 \mathrm{~mm}$,insert thickness- $4 \mathrm{~mm}$,nose radius- $0.4 \mathrm{~mm}$.

According to Taegutec catalog, ISO coding tool holder TCLNL 2525M12 has been used for both negetive insert and positive insert.

\subsection{Input and Output Factors}

In present study,the five parameters viz.speed,feed,depth of cut,insert and work piece material are taken as input process factors.Each parameter has two levels of values as mentioned in Table 3. Surface roughness can generally be described as the geometric features of the surface. Surface roughness measurement is carried out by using a portable stylus-type profilometer (TR 200, India Tools \& Instruments Co., Mumbai). This instrument is a portable, self-contained instrument for the measurement of surface texture. The parameter evaluations are microprocessor based. The measurement results are displayed on a screen. The Roughness measurements, in the transverse direction, on the work pieces has been repeated three times and average of three measurements of surface roughness parameter values has been recorded.

\section{Table 3}

Input Factors and their levels

\begin{tabular}{llllll}
\hline \multirow{2}{*}{ Level } & Factor & \multicolumn{5}{l}{} \\
\cline { 2 - 6 } & Insert & W/P material & $\begin{array}{l}\text { cutting speed } \\
(\mathrm{m} / \mathrm{min})\end{array}$ & $\begin{array}{l}\text { feed } \\
(\mathrm{mm} / \mathrm{rev})\end{array}$ & Doc $(\mathrm{mm})$ \\
\hline 1 & CN1500 & EN-8 & 100 & 0.25 & 1 \\
2 & CC8020 & EN-31 & 150 & 0.30 & 1.5 \\
\hline
\end{tabular}

Initial and final weights of work piece are noted. Machining time is also recorded. Following equations are used to calculate the response Material Removal Rate (MRR):

$\operatorname{MRR}\left(\mathrm{mm}^{3} / \mathrm{min}\right)=\frac{[\text { Initial Weight of workpiece }(\mathrm{gm})-\text { Final Weight of workpiece }(\mathrm{gm})]}{\text { Density }\left(\mathrm{gm} / \mathrm{mm}^{3}\right) \times \text { Machining Time }(\mathrm{min})}$ 
Density of work piece is taken $7.8 \times 10^{-3} \mathrm{gm} / \mathrm{mm}^{3}$.

\subsection{Experimental Design}

For the experimental design Taguchi method was employed. Hence, it has been possible to reach more comprehensive a result with fewer experiments. The objective of Design of experiment is to determine the variables in a process that are the critical parameters and their target values. On the basis of selected parameters, experimental design is carried out. Taguchi method is a powerful tool for the design of high quality systems. It provides simple, efficient and systematic approach to optimize designs for performance, quality and cost (Aslan, 2007). Taguchi method is efficient method for designing process that operates consistently and optimally over a variety of conditions. To determine the best design it requires the use of a strategically designed experiment (Adeel et al., 2008). The Taguchi experimental design is done for $\mathrm{L}_{8} \mathrm{OA}$ for five parameters which are insert, work piece material, speed, feed and depth of cut. Table 4 shows complete design matrix with coded variables as well as actual value of these variable.

\section{Table 4}

Design matrix of experiments

\begin{tabular}{|c|c|c|c|c|c|c|c|c|c|}
\hline \multirow[b]{3}{*}{ Sr. no } & \multicolumn{5}{|c|}{ Actual Variable } & \multicolumn{4}{|c|}{ Responses } \\
\hline & Insert & $\begin{array}{l}\text { Work } \\
\text { piece }\end{array}$ & & $\mathrm{f}$ & & $\begin{array}{l}\text { Surfac } \\
(\mu \mathrm{m})\end{array}$ & ughness & $\begin{array}{l}\text { MRR } \\
\left(\mathrm{mm}^{3} / \mathrm{min}\right.\end{array}$ & \\
\hline & type & material & $(\mathrm{m} / \mathrm{min})$ & $(\mathrm{mm} / \mathrm{rev})$ & $(\mathrm{mm})$ & set -1 & set -2 & set -1 & set -2 \\
\hline 1 & CN1500 & EN-8 & 100 & 0.25 & 1 & 1.568 & 1.513 & 8452.387 & 9604.9 \\
\hline 2 & CN1500 & EN-8 & 100 & 0.3 & 1.5 & 1.841 & 1.99 & 6423.141 & 15567.8 \\
\hline 3 & CN1500 & EN-31 & 150 & 0.25 & 1 & 1.401 & 1.747 & 10989.54 & 12040.3 \\
\hline 4 & CN1500 & EN-31 & 150 & 0.3 & 1.5 & 1.855 & 1.755 & 10935.79 & 19723.9 \\
\hline 5 & CC8020 & EN-8 & 150 & 0.25 & 1.5 & 2.056 & 2.301 & 8343.641 & 21551.7 \\
\hline 6 & CC8020 & EN-8 & 150 & 0.3 & 1 & 2.976 & 2.736 & 7014.732 & 13062.4 \\
\hline 7 & CC8020 & EN-31 & 100 & 0.25 & 1.5 & 2.544 & 2.799 & 4568.939 & 17715.6 \\
\hline 8 & CC8020 & EN-31 & 100 & 0.3 & 1 & 3.107 & 3.503 & 3648.887 & 12190.0 \\
\hline
\end{tabular}

\section{Results and conclusions}

MINITAB statistical software has been used for the analysis of the experimental work. The MINITAB software studies the experimental data and then provides the calculated results of signal-to-noise ratio. In this work, the software has given the signal-to-noise ratio for both the surface roughness and material removal rate. The effect of different process parameters on material removal rate and roughness are calculated and plotted as the process parameters changes from one level to another. The average value of $\mathrm{S} / \mathrm{N}$ ratios has been calculated to find out the effects of different parameters and as well as their levels. The use of both ANOVA (ANalysis Of VAriance) technique and S/N ratio approach makes it easy to analyze the results and hence, make it fast to reach on the conclusion (Aruna, 2010).

\subsection{Analysis of Variance for MRR}

Table 5

Response table for MRR

\begin{tabular}{llllll}
\hline \multirow{2}{*}{ Level } & \multicolumn{5}{c}{ Factors } \\
\cline { 2 - 6 } & Insert & W/P mat & Speed & Feed & D.O.C \\
\hline 1 & 82.64 & 82.77 & 82.66 & 83.02 & 81.16 \\
\hline 2 & $\mathbf{8 3 . 8 1}$ & $\mathbf{8 3 . 6 8}$ & $\mathbf{8 3 . 8}$ & $\mathbf{8 3 . 4 3}$ & $\mathbf{8 5 . 2 9}$ \\
\hline
\end{tabular}


From the response Table 5, it can be seen that an optimum combination of parameters is A2-B2-C2D2-E2. It means that EN 31 gives maximum MRR when machined by CC8020 tool at $150 \mathrm{~m} / \mathrm{min}$ speed, $0.30 \mathrm{~mm} / \mathrm{rev}$ feed and $1.5 \mathrm{~mm}$ depth of cut. The response diagram for each level of the five factors is shown in Fig. 3.

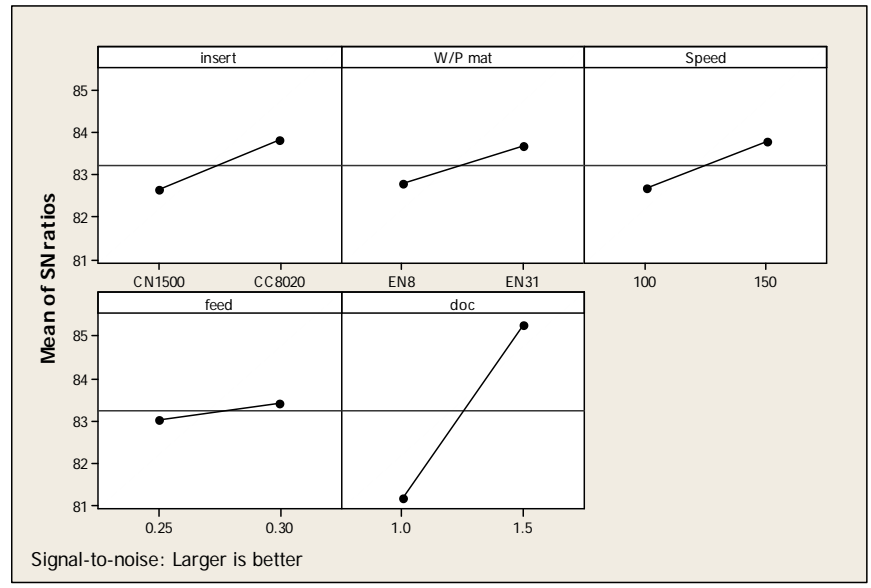

Fig. 3. Response diagram for MRR

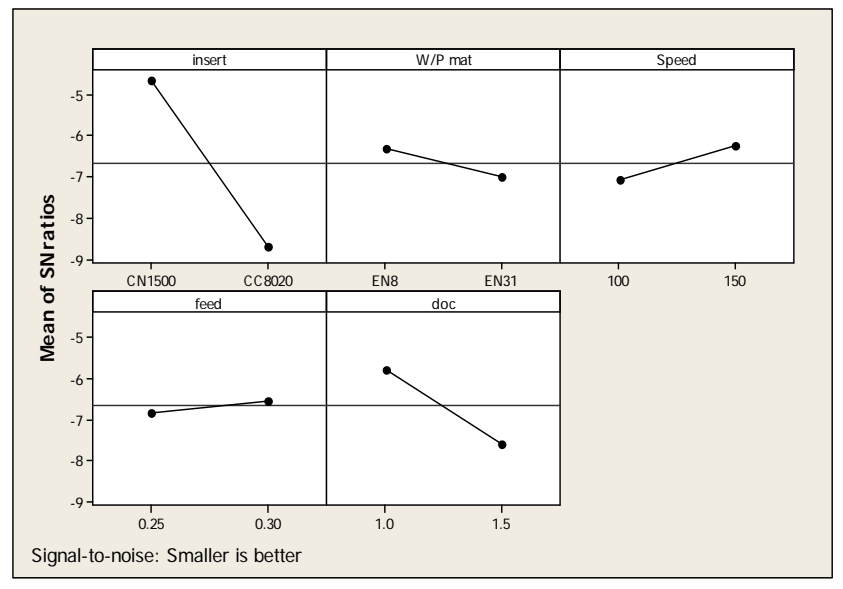

Fig. 4. Response diagram for Surface roughness

From Fig. 3 it can be seen that with increase all three parameters speed, feed and depth of cut, MRR would increase, remarkably, i.e. speed, feed and depth of cut are directly proportional to MRR. In addition, the graph shows that positive inserts are better than the negative inserts and EN-31 materials are superior to EN-8 for MRR.

\section{Table 6}

ANOVA for Material Removal Rate

\begin{tabular}{lllllll}
\hline Source & DF & Seq SS & Adj SS & Adj MS & F & P \\
\hline Insert & 1 & 2.7339 & 2.7339 & 2.7339 & 21.11 & 0.044 \\
W/P mat & 1 & 1.6481 & 1.6481 & 1.6481 & 12.72 & 0.070 \\
Speed & 1 & 2.5768 & 2.5768 & 2.5768 & 19.89 & 0.047 \\
Feed & 1 & 0.3335 & 0.3335 & 0.3335 & 2.57 & 0.250 \\
D.O.C & 1 & 34.1889 & 34.1889 & 34.1889 & 263.97 & 0.004 \\
Residual Error & 2 & 0.2590 & 0.2590 & 0.1295 & & \\
\hline Total & 7 & 41.7401 & & & & \\
\hline
\end{tabular}

Table 6 shows the analysis of variance for material removal rate. It is clear from the table that depth of cut is the most significant factor for material removal rate. Effect of feed is insignificant in the present study as compared with other cutting parameters for material removal rate.

\subsection{Analysis of Variance for Surface Roughness}

Table 7

Response table for Surface Roughness

\begin{tabular}{|c|c|c|c|c|c|}
\hline \multirow{2}{*}{ Level } & \multicolumn{5}{|c|}{ Factors } \\
\hline & Insert & W/P mat & Speed & Feed & D.O.C \\
\hline 1 & -4.633 & -6.327 & -7.088 & -6.817 & -5.767 \\
\hline 2 & -8.711 & -7.017 & -6.256 & -6.527 & -7.577 \\
\hline
\end{tabular}

From the response Table 7, it can be seen that an optimum combination of parameters is A1-B1-C2D2-E1. It means that EN 8 gives minimum surface roughness when machined by CN1500 tool at 150 $\mathrm{m} / \mathrm{min}$ speed, $0.30 \mathrm{~mm} / \mathrm{rev}$ feed and $1 \mathrm{~mm}$ depth of cut. From Fig. 4 it can be seen that in case of 
positive insert surface roughness would increase as compared with use of negative inserts. In addition, the graph shows that CVD coated inserts are better than PVD coated for a surface roughness. It is noted that machinability of EN-8 is better than EN-31. In case of cutting speed, if cutting speed is low then surface roughness would increase and vice versa. If feed is increased then surface roughness would decrease. In the case when depth of cut is increased then surface roughness would increase.

\section{Table 8}

ANOVA for Surface Roughness analysis

\begin{tabular}{lllllll}
\hline Source & DF & Seq. SS & Adj. SS & Adj. MS & F & P \\
\hline Insert & 1 & 33.2590 & 33.2590 & 33.2590 & 326.46 & 0.003 \\
W/P mat & 1 & 0.9540 & 0.9540 & 0.9540 & 9.36 & 0.092 \\
Speed & 1 & 1.3828 & 1.3828 & 1.3828 & 13.57 & 0.066 \\
Feed & 1 & 0.1687 & 0.1687 & 0.1687 & 1.66 & 0.327 \\
D.O.C & 1 & 6.5489 & 6.5489 & 6.5489 & 64.28 & 0.015 \\
Residual Error & 2 & 0.2038 & 0.2038 & 0.1019 & & \\
\hline Total & 7 & 42.5171 & & & & \\
\hline
\end{tabular}

Table 8 shows the analysis of variance for surface roughness. It is clear from the table that insert is the most significant factor for surface roughness. Effect of feed and speed are insignificant in the present study as compare to depth of cut for surface roughness.

\section{Conclusion}

Turning tests were performed on different grades of EN materials using two different inserts of coated carbides cutting tools. The influences of cutting speed, tool inserts type and work piece material were investigated on the machined surface roughness. Based on the results obtained, the following conclusions can be drawn:

1) The analysis of the experimental observations highlights that MRR in CNC turning process is greatly influenced by depth of cut.

2) It is found that if speed is increase then MRR would increase and positive inserts are superior as compare to negative inserts for more MRR.

3) Analysis of Variance suggests the insert is the most significant factor for surface roughness.

\section{References}

Adeel, H., Suhail, N., Ismail, Wong, S.V., \& Abdul Jalil, N.A. (2010). Optimization of cutting parameters based on surface roughness and assistance of work piece surface temperature in turning process. American Journal of Engineering and Applied Sciences, 3(1), 102-108.

Aruna, M., Dhanalaxmi, V., \& Mohan, S. (2010). Wear analysis of ceramic cutting tools in finish turning of Inconel 718. International Journal of Engineering Science and Technology, 2(9), 42534262.

Arora, R.S. (2010). Hand book of mechanical engineering. Academic (INDIA) Publishers, New Delhi.

Aslan, E., Camuşcu, N., \& Birgören, B. (2007). Design optimization of cutting parameters when turning hardened AISI 4140 steel (63 HRC) with Al2O3 + TiCN mixed ceramic tool. Materials \& Design, 28(5), 1618-1622.

Kaladhar, M., Subbaiah, V.S., Rao, Ch. S., \& Rao, K.N. (2010). Optimization of process parameters in turning of AISI 202 Austenitic Stainless Steel. ARPN Journal of Engineering and Applied Sciences, 5(9), 79-87.

Jayant, A., \& Kumar, V. (2008) Prediction of Surface Roughness in CNC Turning Operation using Taguchi Design of Experiments, IE(I) Journal-PR, 88, 19-25.

Thamizhmanii, S., Saparudin, S., \& Hasan, S. (2007). Analyses of surface roughness by turning process using Taguchi method, Journal of Achievements of Materials and manufacturing Engineering, 20, 503-506. 